\title{
Configurações
}

Revista Ciências Sociais

\section{Género(s) e sexualidade(s): uma experiência de ensino em contexto académico}

Gender(s) and sexuality(ies): a teaching experience in academia

Genre(s) et sexualité(s) : une expérience d'enseignement en milieu universitaire

ANA MARIA BRANDÃO, SÉRGIO ANTÔNIO SILVA RÊGO e JOANA TEIXEIRA FERRAZ DA SILVA

\section{OpenEdition}

Journals

Edição electrónica

URL: https://journals.openedition.org/configuracoes/14010

DOI: 10.4000/configuracoes. 14010

ISSN: $2182-7419$

Editora

Centro de Investigação em Ciências Sociais

Edição impressa

Paginação: 83-104

ISSN: 1646-5075

\section{Refêrencia eletrónica}

ANA MARIA BRANDÃO, SÉRGIO ANTÔNIO SILVA RÊGO e JOANA TEIXEIRA FERRAZ DA SILVA,

"Género(s) e sexualidade(s): uma experiência de ensino em contexto académico», Configurações [Online], 28 | 2021, posto online no dia 15 dezembro 2021, consultado o 28 dezembro 2021. URL: http://journals.openedition.org/configuracoes/14010 ; DOl: https://doi.org/10.4000/configuracoes. 14010 
BRANDÃO, Ana Maria; RÊGO, Sérgio Antônio Silva; SILVA, Joana Teixeira Ferraz da - Género(s) e sexualidade(s): uma experiência de ensino em contexto académico.Configurações [em linha]. 28 (2021) p. 83-104.

\title{
Género(s) e sexualidade(s): uma experiência de ensino em contexto académico ${ }^{1}$
}

\author{
ANA MARIA BRANDÃO* \\ Departamento de Sociologia do Instituto de Ciências Sociais da Universidade do Minho e Centro Interdisciplinar \\ de Ciências Sociais - Polo da Universidade do Minho (CICS.NOVA.UMinho) \\ SÉRGIO ANTÔNIO SILVA RÊGO** \\ Centro Interdisciplinar de Ciências Sociais - Polo da Universidade do Minho (CICS.NOVA.UMinho) \\ JOANA TEIXEIRA FERRAZ DA SILVA*** \\ Centro Interdisciplinar de Ciências Sociais - Polo da Universidade do Minho (CICS.NOVA.UMinho)
}

\begin{abstract}
Resumo
O género e a sexualidade são domínios altamente politizados e propen sos a investimentos emocionais e morais. Frequentemente, os seus públicos apresentam perfis favoráveis à diversidade, mas também expectativas de melhorar o autoconhecimento e obter instrumentos para a praxis. Quando provenientes de percursos formativos distintos, a atividade docente pode tornar-se particularmente desafiante. Neste artigo, parte-se dos dados de um inquérito a estudantes, de registos de avaliação da aprendizagem e da experiência docente acumulada para discutir as vantagens de estratégias pedagógicas interativas e participativas que permitem transformar a diversidade interna de uma turma numa oportunidade de aprendizagem académica, pessoal e coletiva.
\end{abstract}

Palavras-chave: Género e sexualidade, metodologias de ensino-aprendizagem, públicos, Ensino Superior, Sociologia.

\footnotetext{
1 Este artigo é uma versão revista e aumentada da comunicação "Corpo(s), género(s) e sexualidade(s): Uma experiência de ensino em contexto académico", apresentada no XI Congresso Português de Sociologia. Identidades ao Rubro, organizado pela Associação Portuguesa de Sociologia, ESPP/ ISCTE-IUL e ICS-ULisboa, no dia 31 de março de 2021 


\section{Abstract \\ Gender(s) and sexuality(ies): a teaching experience in academia}

Gender and sexuality are highly politicised domains surrounded by emotional and moral investments. Their audiences are often favourable to human diversity, but they also bring along expectations for improving self-knowledge and obtaining tools for praxis. When they come from different graduation courses, teaching can become particularly challenging. In this article, data from a student survey, learning assessment records and accumulated teaching experience are used to discuss the advantages of interactive and participatory teaching-learning strategies that make it possible to transform the internal diversity of a class into an opportunity for academic, personal and collective learning.

Keywords: Gender and sexuality, teaching-learning methodologies, audiences, Higher Education, Sociology.

\section{Resumé}

\section{Genre(s) et sexualité(s) : une expérience d'enseignement en milieu universitaire}

Le genre et la sexualité sont des domaines hautement politisés et sujets à des investissements émotionnels et moraux. Leurs publics présentent souvent des profils favorables à l'acceptation de la diversité, mais aussi des attentes d'amélioration de la connaissance de soi et des outils pour la praxis. Quand ils sont issus de parcours de formation différents, l'activité d'enseignement peut devenir particulièrement exigeante. Dans cet article, les données d'une enquête auprès des étudiants, les données d'évaluation des apprentissages et l'expérience d'enseignement accumulée sont utilisées pour discuter des avantages des stratégies d'enseignement interactives et participatives qui permettent de transformer la diversité interne d'une classe en une opportunité d'apprentissage académique, personnel et collectif.

Mots-clés: genre et sexualité, méthodologies d'enseignement-apprentissage, publics , sociologie.

\section{Introdução}

O género e a sexualidade têm-se afirmado como objetos transversais de diversas disciplinas científicas. O investimento dos/as sociólogos/as portugueses/as nestes domínios por via de projetos de investigação científica, comunicações e publicações em revistas de referência nacionais e internacionais tem sido consistente e notório. Todavia, ao passo que, noutras realidades, tem sido também prestada atenção ao ensino de temáticas ligadas ao género e à sexualidade, praticamente nada existe publicado acerca da experiência nacional.

No ano letivo de 2006/2007, o plano de estudos da Licenciatura em Sociologia da Universidade do Minho passou a incluir, no 2. ano, a Unidade 
Curricular (UC) opcional Género e Sexualidade. A designação e o Programa da UC sofreram mudanças desde a sua criação, resultantes da avaliação da experiência de docência. ${ }^{2}$ Situando-se no campo da Sociologia, os seus conteúdos programáticos não se fecham, todavia, ao contributo de outras disciplinas, percorrendo as principais abordagens teóricas do género e da sexualidade em articulação com temáticas concretas e diversas - e.g., a crítica ao modelo androcêntrico de conhecimento, a divisão sexual do trabalho, a violência de género, a discriminação com base na orientação sexual e no género ou a emergência de novas formas de cidadania ligadas ao género e à sexualidade.

Entre os objetivos gerais da UC, encontram-se os de incentivar a reflexão crítica dos/as estudantes acerca dos fenómenos do género e da sexualidade, transmitir conhecimentos fundamentais nestes domínios e desenvolver a capacidade de os aplicar à análise de situações e fenómenos concretos. A metodologia de ensino-aprendizagem foi concebida para apoiar a sua concretização, em consonância com as propostas de Pinto (1994, p. 30).

No ano letivo de 2012/2013, a disciplina passou a integrar uma bolsa de UC aberta a todos os percursos formativos da Universidade do Minho, a $O p c ̧ a \tilde{o}$ UMinho, que visa "a formação integral dos estudantes, proporcionando-lhes não só o domínio de saberes específicos das áreas científicas e profissionais, como o desenvolvimento de saberes transversais, considerados fundamentais para a plena [formação] dos estudantes enquanto pessoas, cidadãos e profissionais" (Despacho Reitoral 05/2015, de 22 de setembro de 2015, n. ${ }^{\circ}$ 1). Embora já fosse procurada por estudantes de outros ciclos de estudos enquanto disciplina extracurricular, a partir desse ano, a turma passou a incluir regularmente um número assinalável de estudantes de outras licenciaturas. Isto representou um novo desafio pedagógico na medida em que, para públicos sem contacto prévio com a Sociologia - e, por vezes, bastante distantes dela -, certos conceitos e abordagens podem ser mais desafiantes.

No ano letivo de 2020/21, procurou-se sistematizar e consolidar as perceções resultantes de vários anos de ensino lançando um inquérito aos/às estudantes inscritos/as na UC através de um questionário em linha de administração direta. A interação em sala de aula ao longo do tempo sugeria, por um lado, que os públicos da UC apresentavam maior sensibilidade a fenómenos de desigualdade e discriminação ligados ao género e à sexualidade e, por outro, que procuravam obter e sistematizar conhecimentos que permitissem interpretá-los. Era também mais ou menos evidente a vivência de experiências pessoais que impeliam a procura de instrumentos que lhes permitissem situar-se dos pontos de vista pessoal e social. O questionário que serviu de base a esse inquérito visou, portanto, traçar o perfil dos/as públicos da UC, conhecer

2 No ano letivo de 2012/13, passa a designar-se Corpo, Género e Sexualidade. Retoma a designação inicial na Proposta de Alteração do Plano de Estudos submetida no final de 2019 à Agência de Avaliação e Acreditação do Ensino Superior (A3ES), versão tomada aqui como referência. 
as motivações que subjazem à escolha desta e proporcionar um conhecimento aproximado dos seus valores, atitudes e representações face a questões ligadas ao género e à sexualidade.

Neste artigo, parte-se dos dados desse inquérito, de registos de avaliação da aprendizagem para o mesmo ano letivo e do conhecimento docente acumulado para discutir as vantagens da metodologia de ensino-aprendizagem adotada. Começa-se por apresentar o perfil sociodemográfico e as motivações dos públicos da UC. Depois, parte-se para uma análise dos seus valores, atitudes e representações face ao género e à sexualidade. Os dados destas duas secções mostram uma elevada predisposição dos/as estudantes para a aceitação da diversidade e são mobilizados para dar conta dos desafios pedagógicos que suscitam. Num terceiro momento, discute-se a estratégia pedagógica adotada considerando os objetivos de aprendizagem da UC e as características dos seus públicos. Argumenta-se que as diferenças na composição destes, colocando desafios à atividade docente, podem ser também encaradas como oportunidades valiosas de aprendizagem.

\section{Perfil sociodemográfico e motivações dos públicos da UC}

O inquérito foi lançado no início do $2 .^{\circ}$ semestre letivo e cobriu um total de 36 inquiridos/as, correspondendo a 78,3\% do total de inscritos/as. Todos/as eram solteiros/as, predominantemente nascidos/as na década de 2000 (25 casos, $69,4 \%$ ) e estudantes a tempo inteiro (33 casos, 91,7\%), como ilustram as tabelas 1 e 2 . Daqui resulta uma maior homogeneidade desta turma face às de anos anteriores no que respeita às variáveis elencadas.

Tabela 1 - Década de nascimento

\begin{tabular}{|l|c|}
\hline Década de nascimento & $\begin{array}{c}\mathbf{N} \\
\mathbf{( \% )}\end{array}$ \\
\hline Década de 1980 & 1 \\
& $(2,8)$ \\
\hline Década de 1990 & 9 \\
& $(25,0)$ \\
\hline Década de 2000 & 25 \\
& $(69,4)$ \\
\hline N.R. & 1 \\
& $(2,8)$ \\
\hline Total & 36 \\
& $(100,0)$ \\
\hline
\end{tabular}


Tabela 2 - Situação ocupacional

\begin{tabular}{l|r}
\hline Situação ocupacional & \multicolumn{2}{|c}{$\begin{array}{c}\text { N } \\
(\%)\end{array}$} \\
\hline Encontra-se apenas a estudar & 33 \\
& $(91,7)$ \\
\hline Exerce uma atividade & 1 \\
profissional & $(2,8)$ \\
\hline Outra situação & 2 \\
& $(5,6)$ \\
\hline Total & 36 \\
& $(100,0)$ \\
\hline
\end{tabular}

Embora essa maior homogeneidade possa facilitar a atividade docente devido à similaridade de interesses e experiências dos/as estudantes/as, também pode traduzir-se numa perda formativa. Como notam Kramer e Martin Jr. (1988), a presença de estudantes de diferentes idades e que já assumiram papéis próprios da vida adulta - e.g., pelo exercício de uma atividade profissional ou pela experiência da parentalidade - implica maior sensibilidade a certas temáticas e oferece contrastes geracionais interessantes.

Sem surpresa, as estudantes eram também maioritárias (31 inquiridas, $86 \%$ do total), como mostra o gráfico 1 .

\section{Gráfico 1 - Identidade de género reclamada}

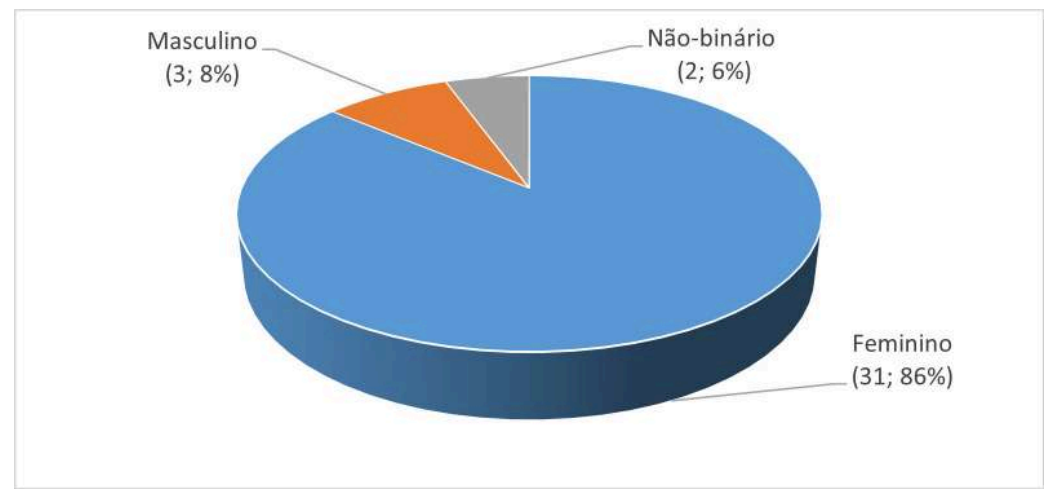

De facto, embora as turmas apresentem variações anuais de acordo com o género, as estudantes têm estado sempre sobrerrepresentadas, uma constatação recorrente de quem ensina e investiga nestes domínios. A ideia de que, neste tipo de UC, se trata de questões com pouca ou nenhuma relevância (em geral, ou especialmente para os homens), o receio dos estudantes de serem considerados gays ou objeto de crítica por serem homens durante as aulas são algumas 
das razões aventadas (ver Kramer e Martin Jr., 1988, p. 137; Lieberman, 2017). Mas é também possível que não tenhamos tido, ainda, a capacidade de demonstrar a relevância dos fenómenos ligados ao género e à sexualidade para os estudantes, em particular, e para os homens, em geral, como sugere Lieberman (2017).

Destaca-se, entretanto, a presença de estudantes que reclamam uma identidade de género não-binária (2 casos, 5,6\%), i.e., uma identidade nem masculina, nem feminina, e não heterossexuais ( 15 casos, $42 \%$ do total), patente no gráfico 2 , outras duas constantes.

\section{Gráfico 2 - Orientação sexual reclamada}

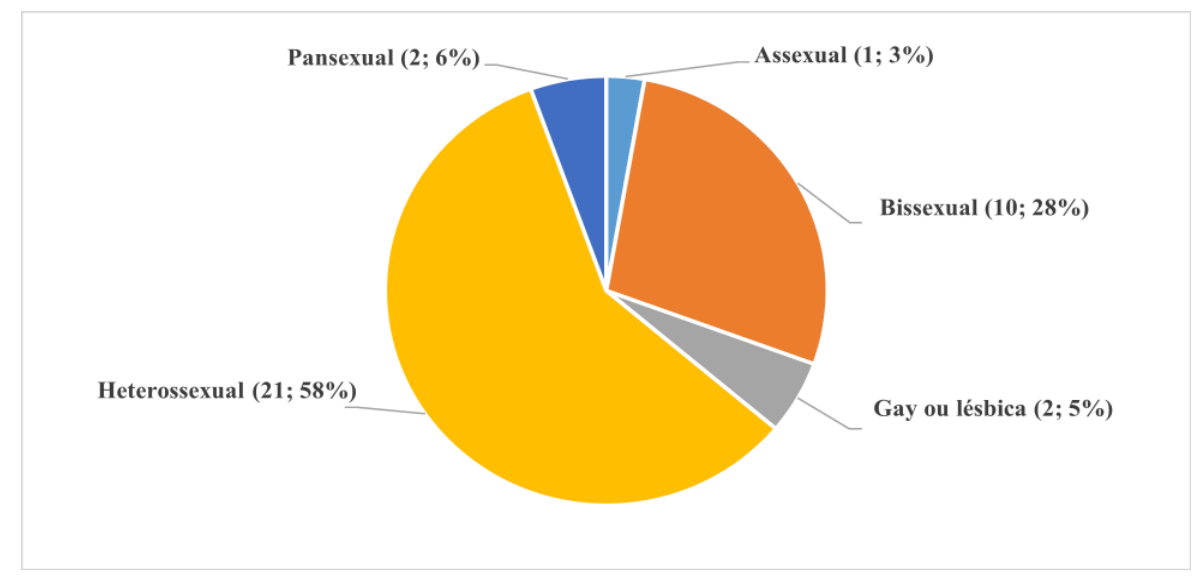

Os dados mostram, assim, uma sobrerrepresentação de estudantes não heterossexuais face ao conjunto da população portuguesa (ver Aboim, 2010; Marques, 2012), potenciando o risco de as aulas se transformarem "em grupos de conscientização ou terapia", já que este domínio de estudos favorece a autorrevelação, em contexto de aula e fora dela (Berheide e Segal, 1985, p. 278). Contanto que se consiga converter esse risco num ganho pedagógico, todavia, isso pode ser uma mais-valia quer em termos coletivos, quer em termos pessoais para os/as estudantes em causa, que podem encontrar nas aulas um espaço suficientemente seguro para expor as suas dúvidas, experiências e preocupações. O sentimento de segurança pode, de resto, ser potenciado pela composição da turma, favorecendo a exposição, já que a pertença a algum tipo de minoria pode reduzir a participação nas aulas (Davis, 2005, p. 30; Lee, 1993, p. 30). É, todavia, fundamental ter presente que esse sentimento pode também ser gorado quer por intervenções de colegas no contexto da aula sentidas como discriminatórias, quer pela revelação de informação sensível a terceiros fora dela (Davis, 2005; Lee, 1993; Francis, 2021). Esse risco exige que 
o/a docente estabeleça com clareza, logo no início do semestre, certas regras de conduta dentro da sala de aulas e que seja capaz de transformar essas ocasiões em momentos de aprendizagem que melhorem a compreensão do Outro, procurando, assim, garantir também o seu cumprimento fora dela.

O questionário incluía também uma questão de resposta múltipla sobre as razões de escolha da UC e duas questões, uma fechada e outra aberta, que visavam determinar se os/as estudantes já tinham tido frequentado alguma disciplina onde lhes tivessem sido transmitidos conhecimentos nos domínios do género e/ou da sexualidade.

Quanto às razões de escolha da UC, elencadas na tabela 3, as duas mais assinaladas são a vontade de aprofundar conhecimentos neste domínio e a curiosidade $(94,4 \%$ e $41,7 \%$ do total de inquiridos/as, respetivamente). Estas razões surgem quase invariavelmente acompanhadas de outras, que remetem para a necessidade de autoconhecimento ou de aquisição de instrumentos de orientação da conduta.

Tabela 3 - Principais razões para se inscrever na UC

\begin{tabular}{|l|r|}
\hline Razões da escolha & $\begin{array}{c}\text { N } \\
(\%)\end{array}$ \\
\hline Para aprofundar conhecimentos no domínio & 34 \\
& $(94,4)$ \\
\hline Por curiosidade & 15 \\
\hline Para saber mais sobre a minha sexualidade & $(41,7)$ \\
\hline Porque pretendo vir a trabalhar/ estudar nestes domínios & 11 \\
& $(30,6)$ \\
\hline Para lidar melhor c/ situações ou experiências de vida que me & 10 \\
incomodam/ incomodaram & $(27,8)$ \\
\hline Para compreender melhor os meus desejos, sentimentos e/ou afetos & 10 \\
& $(27,8)$ \\
\hline Para saber mais sobre a minha identidade de género & 9 \\
& $(25,0)$ \\
\hline Porque as outras UC opcionais não me agradavam & 5 \\
& $(13,9)$ \\
\hline Por influência de colega(s) & 2 \\
& $(5,6)$ \\
\hline
\end{tabular}

Legenda: $\left({ }^{*}\right)$ frequências relativas calculadas, em cada caso, face a $\mathrm{N}$.

Todos/as os/as estudantes que reclamaram uma identidade de género não-binária e algumas estudantes apontaram a vontade de saber mais sobre a sua identidade de género como uma das principais razões de escolha da UC. A vontade de saber mais sobre a própria sexualidade é também mais assinalada por 
estudantes bissexuais (aproximadamente, um terço destes/as) ou pansexuais (metade destes/as) e por todos/as os/as que se definem como gays, lésbicas ou assexuais. Razões como "para lidar melhor c/ situações ou experiências de vida que me incomodam/ incomodaram" ou "para compreender melhor os meus desejos, sentimentos e/ou afetos" apresentam idêntico padrão de resposta. Estes dados confirmam uma perceção recorrente ao longo dos anos: muitos/ as estudantes escolhem a UC na expectativa de encontrar respostas para preocupações de ordem pessoal. Num quadro mais lato, sugerem que há questões ligadas ao género e/ou à sexualidade que permanecem por esclarecer durante a adolescência, juventude e início da idade adulta. E acentuam a necessidade de gerir o equilíbrio delicado entre o respeito pelas preocupações pessoais dos/ as estudantes e o cumprimento dos objetivos de aprendizagem estabelecidos.

Entretanto, se a maioria dos/as inquiridos/as $(25,69,4 \%$ do total) começa por declarar que, ao longo do seu percurso escolar, não frequentou nenhuma disciplina onde lhe tivessem sido transmitidos conhecimentos naqueles domínios, seguidamente todos/as mencionam ter tido contacto com conteúdos relacionados em aulas de Ciências Naturais, como mostra o gráfico 5. E há também quem o tenha tido no âmbito de outras disciplinas e/ou projetos escolares transversais.

\section{Gráfico 3 - Disciplina(s) frequentadas com conteúdos sobre género e/ou sexualidade}

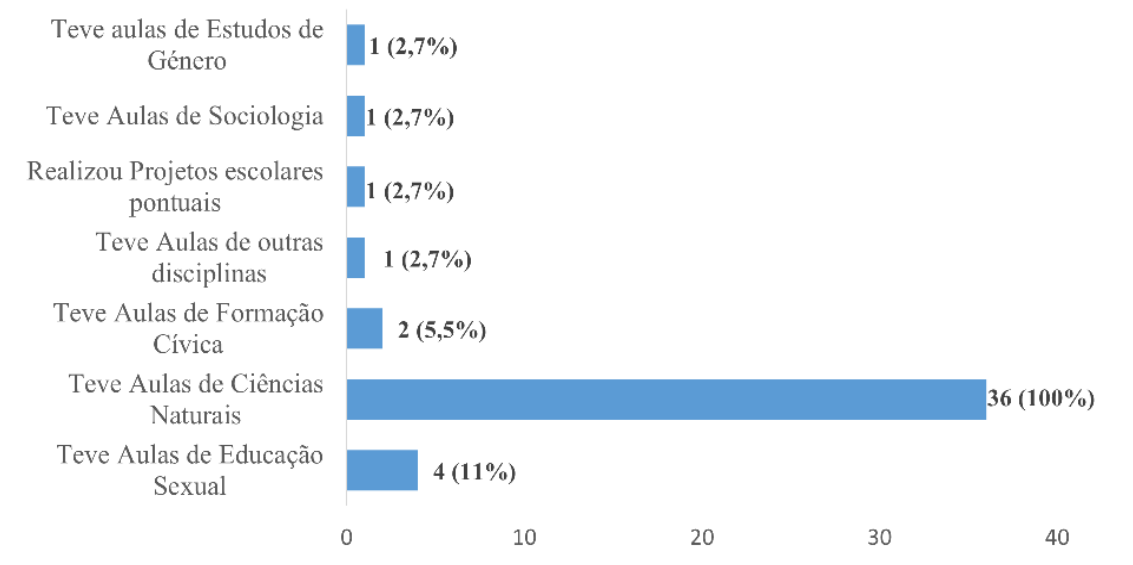

À primeira vista, os resultados são curiosos, considerando que a igualdade de género e a sexualidade têm sido dimensões fundamentais da Educação para a Cidadania implementada nos vários ciclos do ensino básico e secundário (ver Alvarez e Vieira, 2014; Grupo de Trabalho de Educação para a Cidadania, 2017). Todavia, a metodologia de operacionalização desta deixa às escolas 
a escolha dos domínios a trabalhar (ver Decreto-Lei n. 55 de 6 de julho de 2018 da Presidência do Conselho de Ministros, 2018). Assim, as disciplinas de Ciências Naturais, no ensino básico, e de Biologia, no ensino secundário, continuam a ser os contextos mais comuns de transmissão de conteúdos de “educação sexual”, privilegiando a sua dimensão fisiológica (ver, e.g., Matos et al., 2014; Vilar, Ferreira e Duarte, 2008).

Quanto à igualdade de género, o estudo ex ploratório de Seixas (2020, p. 49) junto de docentes responsáveis pela disciplina de Cidadania e Desenvolvimento mostra que estes/as identificam dois tipos fundamentais de obstáculos à sua operacionalização: a persistência de visões estereotipadas do género quer das famílias, quer dos/as próprios/as estudantes/as, que sustentam resistências ao tratamento do tema; e dificuldades em dinamizar atividades que apelem ao pensamento crítico destes/as. Este último dado sugere que os/as docentes possam não ter a preparação necessária nestes domínios, problema também identificado por Graupe et al. (2018) no caso do Brasil.

Em conjunto, estes dados podem significar que o contacto com conteúdos ligados ao género e/ou à sexualidade no ensino não superior pode não ter sido uma experiência comum a todos/as os/as estudantes e/ou não ter correspondido aos seus interesses e/ou necessidades.

\section{Valores, atitudes e representações face ao género e à sexualidade}

O questionário incluía uma bateria de escalas de valores, representações e atitudes face ao género e à sexualidade construída a partir das propostas de Nanda (2011), Duncan et al. (2019) e do International Center for Research on Women (ICRW) (2011). As respostas foram organizadas numa escala de Likert de 5 posições, em que 1 = discordo bastante; 2 = discordo; 3 = não concordo, nem discordo; 4 = concordo e 5 = concordo bastante. Os dados obtidos são apresentados em tabelas contendo o valor modal, a mediana e a média respetivos.

Os resultados da tabela 4 sugerem, por um lado, uma elevada consciência da presença de atitudes discriminatórias face à não conformidade de género, i.e., a comportamentos e/ou expressões do género que não se conformam à norma, e a um elevado grau de aceitação desta, tanto por parte dos/as inquiridos/as, como dos seus grupos de pares, a despeito de pequenas variações de grau, como ilustram os valores médio e modal. Além disso, há uma recusa de envolvimento em comportamentos discriminatórios face à não conformidade de género e à não heterossexualidade, também com ligeiras diferenças entre os valores médio e modal. Finalmente, sublinhe-se a crença na ausência de relação entre género normativo e a possibilidade de se ser um modelo a seguir, verificando-se que os valores médios e as medianas resultam de posições 
tendencialmente favoráveis às afirmações "Homens que não são masculinos" e "Mulheres que não são femininas são bons modelos a seguir".

Tabela 4 - Valores, representações e atitudes face ao género

\begin{tabular}{|l|r|r|r|} 
& Moda & Média & Mediana \\
\hline $\begin{array}{l}\text { Já presenciei provocaçães ou intimidação de pessoas que se } \\
\text { vestissem ou agissem como alguém do outro sexo/género }\end{array}$ & 5 & 3,33 & 4 \\
\hline $\begin{array}{l}\text { Já ouvi opiniões negativas sobre pessoas que se vestem ou agem } \\
\text { como sendo do outro sexo/ género }\end{array}$ & 5 & 4,81 & 5 \\
\hline $\begin{array}{l}\text { No passado, já provoquei ou intimidei alguém que se vestia ou } \\
\text { agia como sendo do outro sexo }\end{array}$ & 1 & 1,22 & 1 \\
\hline $\begin{array}{l}\text { No passado, já fui provocado/a ou intimidado/a por agir como } \\
\text { sendo do outro sexo/ género }\end{array}$ & 1 & 1,61 & 1 \\
\hline $\begin{array}{l}\text { Sinto-me limitado/a por aquilo que as pessoas esperam de } \\
\text { mim por causa do meu sexo/ género }\end{array}$ & 3 & 3,03 & 3 \\
\hline $\begin{array}{l}\text { E possivel respeitar a minha cultura e aceitar as pessoas que se } \\
\text { sentem romântica ou sexualmente atraídas por pessoas do } \\
\text { mesmo sexo }\end{array}$ & 5 & 4,97 & 5 \\
\hline $\begin{array}{l}\text { E possível respeitar a minha religião e aceitar as pessoas que se } \\
\text { sentem romântica ou sexualmente atraídas por pessoas do } \\
\text { mesmo sexo }\end{array}$ & 5 & 4,97 & 5 \\
\hline $\begin{array}{l}\text { Os meus amigos aceitam bem pessoas que não se conformam } \\
\text { aos papéis de género tradicionais }\end{array}$ & 5 & 4,31 & 5 \\
\hline $\begin{array}{l}\text { Os meus amigos aceitam bem pessoas que se sentem romântica } \\
\text { ou sexualmente atraídas por pessoas do mesmo sexo/ género }\end{array}$ & 5 & 4,56 & 5 \\
\hline Incomodam-me os homens que têm maneirismos femininos & 1 & 1,22 & 1 \\
\hline Incomodam-me as mulheres que têm maneirismos masculinos & 1 & 1,14 & 1 \\
\hline Prefiro que os homens sejam femininos em vez de masculinos & 3 & 2,5 & 3 \\
\hline Prefiro que as mulheres sejam masculinas em vez de femininas & 3 & 3,33 & 3 \\
\hline Homens que não são masculinos são bons modelos a seguir & 3 & 3,64 & 3 \\
\hline Mulheres que não são femininas são bons modelos a seguir & 3 & 3,5 & 3 \\
\hline $\begin{array}{l}\text { Não acho que seja inteiramente natural, para algumas pessoas, } \\
\text { vestirem-se e agirem como se fossem do outro sexo/ género }\end{array}$ & 1 & 1,28 & 1 \\
\hline $\begin{array}{l}\text { Não me sinto confortável em socializar com pessoas que se } \\
\text { vestem, agem ou se identificam abertamente sendo de um sexo/ } \\
\text { género diferente daquele com que nasceram }\end{array}$ & 1,08 & 1 & 1 \\
\hline $\begin{array}{l}\text { Não associo pessoas que se vestem ou agem como sendo do } \\
\text { outro sexo/ género a tendências homossexuais }\end{array}$ & 5 & 3,53 & 4 \\
\hline
\end{tabular}

Estas respostas podem ser explicadas quer pela composição do universo no que respeita à identidade de género e à orientação sexual, quer pelo facto de um elevado número de inquiridos/as conhecer outras pessoas não heterossexuais (34 inquiridos/as, 94,4\% do total) e/ou trans (23 inquiridos/as, 63,9\% do total). 
É, ainda, importante notar a proximidade entre os valores médio, modal e da mediana face à afirmação "Sinto-me limitado/a por aquilo que as pessoas esperam de mim por causa do meu sexo/ género", todos situados no - ou próximo do - ponto central da escala. As respostas concordantes são assinaladas por 2 dos 3 inquiridos que reclamam uma identidade masculina $(66,7 \%$ do total destes), por 10 inquiridas que reclamam uma identidade feminina $(32,3 \%$ do total destas) e pela totalidade dos/as que reclamam uma identidade de género não-binária. Note-se, igualmente, que a posição central da escala é assinalada unicamente por inquiridas que reclamam uma identidade feminina (10 inquiridas, 32,3\% do total destas). Por outras palavras, apenas 12 inquiridos/ as $(33,3 \%$ do total global) discordam da afirmação, sugerindo a presença de visões algo críticas face ao género normativo e à sua relação com a identidade. De resto, quer as posições de concordância, quer a posição central tendem a ser mais assinaladas pelos/as bissexuais (9 casos, $90 \%$ do total respetivo) e por gays/lésbicas ( 2 casos, $100 \%$ do total respetivo), embora sejam também escolhidas por um pouco mais de metade dos/as heterossexuais (11 inquiridos/as, $53,3 \%$ do total respetivo).

De forma não surpreendente face aos resultados anteriores, a tabela 5 mostra que a esmagadora maioria dos/as estudantes tem posições favoráveis à igualdade de direitos das minorias sexuais e rejeita a associação entre homossexualidade e patologia, também com ligeiras variações entre os valores médio e modal. Apesar disso, as respostas a questões que remetem para a etiologia da homossexualidade suscitam reflexões adicionais.

Tabela 5 - Valores, representações e atitudes face à sexualidade

\begin{tabular}{|l|r|r|r|}
\hline & Moda & Média & Mediana \\
\hline $\begin{array}{l}\text { Devem ser garantidos direitos e proteção iguais a todas as } \\
\text { pessoas, incluindo pessoas que se sentem romântica ou } \\
\text { sexualmente atraídas por pessoas do mesmo sexo }\end{array}$ & 5 & 5 \\
\hline $\begin{array}{l}\text { Todos/as os/as trabalhadores/as, incluindo aqueles/as que se } \\
\text { sentem romântica ou sexualmente atraídos/as por pessoas do } \\
\text { mesmo sexo, devem ser protegidos/as da discriminação no local } \\
\text { de trabalho e no acesso ao emprego }\end{array}$ & 5 & 4,83 & 5 \\
\hline $\begin{array}{l}\text { A homossexualidade não é uma fase que crianças ou } \\
\text { adolescentes acabem por superar }\end{array}$ & $\mathbf{5}$ & $\mathbf{4 , 6 9}$ & $\mathbf{5}$ \\
\hline $\begin{array}{l}\text { Não há boas probabilidades de conseguir transformar } \\
\text { pessoas homossexuais em homens e mulheres heterossexuais }\end{array}$ & $\mathbf{5}$ & $\mathbf{4 , 4 2}$ & $\mathbf{5}$ \\
\hline A orientação sexual estabelece-se desde cedo & $\mathbf{3}$ & $\mathbf{3 , 5}$ & $\mathbf{3 , 5}$ \\
\hline A homossexualidade não é uma perversão & 5 & 5 \\
\hline $\begin{array}{l}\text { A homossexualidade é apenas um estilo de vida diferente que } \\
\text { não deve ser condenado }\end{array}$ & $\mathbf{5}$ & $\mathbf{4 , 2 8}$ & $\mathbf{5}$ \\
\hline $\begin{array}{l}\text { Pessoas que se envolvem em relacionamentos românticos ou } \\
\text { sexuais com pessoas do mesmo sexo não devem ser } \\
\text { criminalizadas }\end{array}$ & 5 & 5,81 & 5 \\
\hline $\begin{array}{l}\text { A identidade declarada pelas pessoas que se vestem, agem ou se } \\
\text { identificam com um determinado sexo/ género, embora tenham } \\
\text { nascido com outro, deve ser sempre legalmente reconhecida }\end{array}$ & 5 & 5 \\
\hline
\end{tabular}


Há quem discorde ou hesite quanto ao facto de a homossexualidade não ser uma fase que crianças ou adolescentes acabem por superar (2 inquiridos/ as discordam bastante, 5,6\% do total), quanto à possibilidade de se conseguir transformar pessoas homossexuais em homens e mulheres heterossexuais (3 inquiridos/as discordam bastante, $8,3 \%$ do total) e quanto à possibilidade de a homossexualidade ser apenas um estilo de vida diferente que não deve ser condenado (2 inquiridos/as discordam ou discordam bastante, 5,6\% do total). Refira-se, ainda, 1 caso $(2,8 \%)$ em que há discordância face à proteção de todos/as os/as trabalhadores/as, incluindo daqueles/as que se sentem romântica ou sexualmente atraídos por pessoas do mesmo sexo, da discriminação no local de trabalho e no acesso ao emprego, e outro caso $(2,8 \%)$ em que é assinalada a posição neutra, em aparente contradição com as respostas à afirmação anterior, que defende a garantia de "direitos e proteção iguais a todas as pessoas, incluindo pessoas que se sentem romântica ou sexualmente atraídas por pessoas do mesmo sexo". A análise das posições face a estas afirmações, cuzada com as variáveis sociodemográficas ou outras incluídas no questionário, não permitiu encontrar pistas explicativas, o que pode ter que ver com a pouca variação do universo face à generalidade das variáveis sociodemográficas consideradas. Apenas se pôde verificar que as respostas mais conservadoras foram típica, mas não exclusivamente, assinaladas pelas mesmas 2 ou 3 inquiridas.

Mas é sobretudo no que respeita ao grau de precocidade da orientação sexual que a discordância ou hesitação dos/as inquiridos/as é mais notória, como evidenciam os valores médio e modal e a mediana: 5 discordam ou discordam bastante da afirmação "A orientação sexual estabelece-se desde cedo" $(13,9 \%$ do total) e 13 não concordam, nem discordam dela (36,1\% do total). Trata-se, de resto, de um assunto sobre o qual não existe posição consensual por parte da comunidade científica e que não apresenta, necessariamente, relação com as atitudes face às minorias sexuais.

No que respeita às relações sociais de género, o questionário incluía afirmações incidindo especificamente sobre a sexualidade, a violência nas relações de intimidade e a divisão sexual do trabalho. A tabela 6 permite verificar uma discordância generalizada com visões estereotipadas do género no domínio da sexualidade e uma rejeição clara quer da violência nas relações de intimidade, incluindo a ideia de que se trata de uma questão "privada" do casal, quer de uma divisão de tarefas nos domínios doméstico e público de acordo com linhas de género. 
Tabela 6 - Valores, representações e atitudes face à sexualidade e às relações sociais de género

\begin{tabular}{|c|c|c|c|}
\hline Género e sexualidade: & Moda & Média & Mediana \\
\hline $\begin{array}{l}\text { Os homens têm muitas parceiras sexuais porque isso faz parte } \\
\text { da sua natureza }\end{array}$ & 1 & 1,5 & 1 \\
\hline Os homens precisam mais de sexo do que as mulheres & 1 & 1,56 & 1 \\
\hline As mulheres precisam mais de afeto do que os homens & 1 & 1,03 & 1 \\
\hline $\begin{array}{l}\text { Os homens, muitas vezes, forçam as mulheres de maneiras } \\
\text { subtis a ter sexo com eles, mesmo que elas não queiram }\end{array}$ & 5 & 3,94 & 4 \\
\hline$\dot{\mathrm{E}}$ responsabilidade da mulher evitar engravidar & 1 & 1,47 & 1 \\
\hline $\begin{array}{l}\text { Uma mulher pode sugerir o uso de preservativo, tal como um } \\
\text { homem }\end{array}$ & 5 & 4,86 & 5 \\
\hline Uma mulher não deve tomar a iniciativa nas relações sexuais & 1 & 1,14 & 1 \\
\hline \multicolumn{4}{|l|}{ Violência nas relações de intimidade: } \\
\hline Há momentos em que uma mulher merece apanhar & 1 & 1,03 & 1 \\
\hline $\begin{array}{l}\text { A mulher deve tolerar a violência de que é alvo para manter a } \\
\text { sua familia unida }\end{array}$ & 1 & 1 & 1 \\
\hline Em certas situações, é aceitável agredir o/a parceiro/a & 1 & 1,03 & 1 \\
\hline $\begin{array}{l}\text { Se um homem agride a sua esposa, isso é um assunto privado } \\
\text { que não deve ser discutido fora do casal }\end{array}$ & 1 & 1 & 1 \\
\hline \multicolumn{4}{|l|}{ Divisão sexual do trabalho: } \\
\hline $\begin{array}{l}\text { Mudar fraldas, dar banho e alimentar as crianças é, sobretudo, } \\
\text { responsabilidade da mãe }\end{array}$ & 1 & 1,11 & 1 \\
\hline $\begin{array}{l}\text { Quando há falta de empregos, os homens deveriam ter } \\
\text { prioridade face às mulheres }\end{array}$ & 1 & 1 & 1 \\
\hline As mulheres são melhores lideres políticas do que os homens & 3 & 3,22 & 3 \\
\hline
\end{tabular}

As respostas obtidas em duas das afirmações propostas à apreciação dos/ as estudantes merecem considerações adicionais.

Desde logo, mais de metade dos/as inquiridos/as (25, 69,4\% do total) concorda ou concorda bastante com a ideia de que "Os homens, muitas vezes, forçam as mulheres de maneiras subtis a ter sexo com eles, mesmo que elas não queiram". Tratando-se de um posicionamento face a uma afirmação de ordem factual (e não valorativa) e que retrata, direta ou indiretamente, o seu conhecimento da realidade, estes resultados ilustram a persistência da reconhecida assimetria entre homens e mulheres no que respeita a "condutas sexuais complacentes" (ver Impett e Peplau, 2003).

Sublinhe-se, igualmente, o facto de metade dos/as inquiridos/as assinalar o ponto central da escala no que respeita à relação entre qualidade das lideranças políticas e género, sugerindo uma ausência de relação entre ambos os termos da afirmação. 
As variáveis sociodemográficas também não apresentaram relação visível com a posição dos/as inquiridos/as face a estas afirmações.

\section{Desafios e estratégias pedagógicos}

Se os valores, atitudes e representações dos/as estudantes e o seu interesse pelo subcampo disciplinar da UC podem sugerir uma docência facilitada, não deixam de constituir um desafio. Desde logo, como referido, boa parte deles/as parece procurar nela melhorias ao nível do autoconhecimento e/ou orientações para a conduta. Isto torna-se claro nalgumas respostas à questão aberta incluída no final do questionário, onde se pedia que indicassem os dois temas que mais gostariam de ver tratados nas aulas. Os exemplos seguintes ilustram a correspondência entre as identidades reclamadas pelos/as estudantes e as temáticas que avançam:

A forma como a nossa educação por parte dos pais influencia a nossa perspetiva sobre os diferentes tipos de sexualidade e como informar e educar as gerações mais velhas sobre a aceitação de todo o tipo de pessoas.

(homem bissexual, nascido na década de 2000)

Eu tenho especial interesse em abordar temas relacionados com a sexualidade e atração sexual, principalmente porque sou assexual. O único discurso que eu conhecia, até descobrir o que a assexualidade é, era o de que a necessidade e o desejo por relações sexuais é algo inerente ao ser humano. Então, acho que seria interessante explorar este tema em contex to académico e talvez entender melhor o que é, realmente, a sexualidade.

(mulher assexual, nascida na década de 2000)

A normalização de mulheres em posições de poder e integração social de pessoas trans/não-binárias.

(jovem não-binário/a pansexual, nascido/a na década de 2000)

De facto, a experiência letiva ao longo dos anos sugeria uma maior sensibilidade de certos/as estudantes a temáticas específicas, visível no teor emotivo das suas intervenções durante as aulas, incluindo ocasiões em que decidem proceder a autorrevelações da identidade de género, da orientação sexual e/ou da vivência de certas situações (e.g., violência doméstica). Esse investimento emocional pode ser problemático, dificultando a compreensão da multidimensionalidade dos fenómenos sociais - e, em particular, a necessidade de os situar no plano sociológico, portanto, supra-individual - e comprometendo a objetividade da análise. O/a estudante tem, pois, de ser confrontado com a necessidade de distinguir entre "perturbações pessoais" e "questões públicas 
da estrutura social" (Wright Mills, 1972, p. 14)3. Quando esse investimento se liga à vontade de denunciar - e agir sobre - situações consideradas injustas, o/a docente é também chamado a recordar, de forma mais ou menos sistemática, a distinção entre problema social e problema sociológico, nem sempre evidente, especialmente para não sociólogos/as.

No ano letivo em apreço, como também é habitual, a UC foi escolhida quase em igual proporção por estudantes de Sociologia e de outras licenciaturas, ainda que estas surjam sobrerrepresentadas no inquérito (21 estudantes, $58,3 \%$ do total, face a 15 estudantes, $41,7 \%$ do total, respetivamente), com destaque para os Estudos Literários (13 casos, 36,1\% do total). Considerando a sua agregação por grande domínio científico, ilustrada no gráfico 4, as Ciências Sociais e as Humanidades eram claramente preponderantes (cerca de $83 \%$ do total), seguidas das Ciências Exatas e Engenharias e das Ciências Naturais e do Ambiente ( $8 \%$ e $6 \%$ do total, respetivamente). A diversidade da turma deste ponto de vista suscita questões pedagógicas relevantes, mesmo no caso das Humanidades, que, embora integrando a mesma grande área que as Ciências Sociais, apresentam um perfil formativo distinto.

\section{Gráfico 4 - Curso frequentado por grande domínio científico}

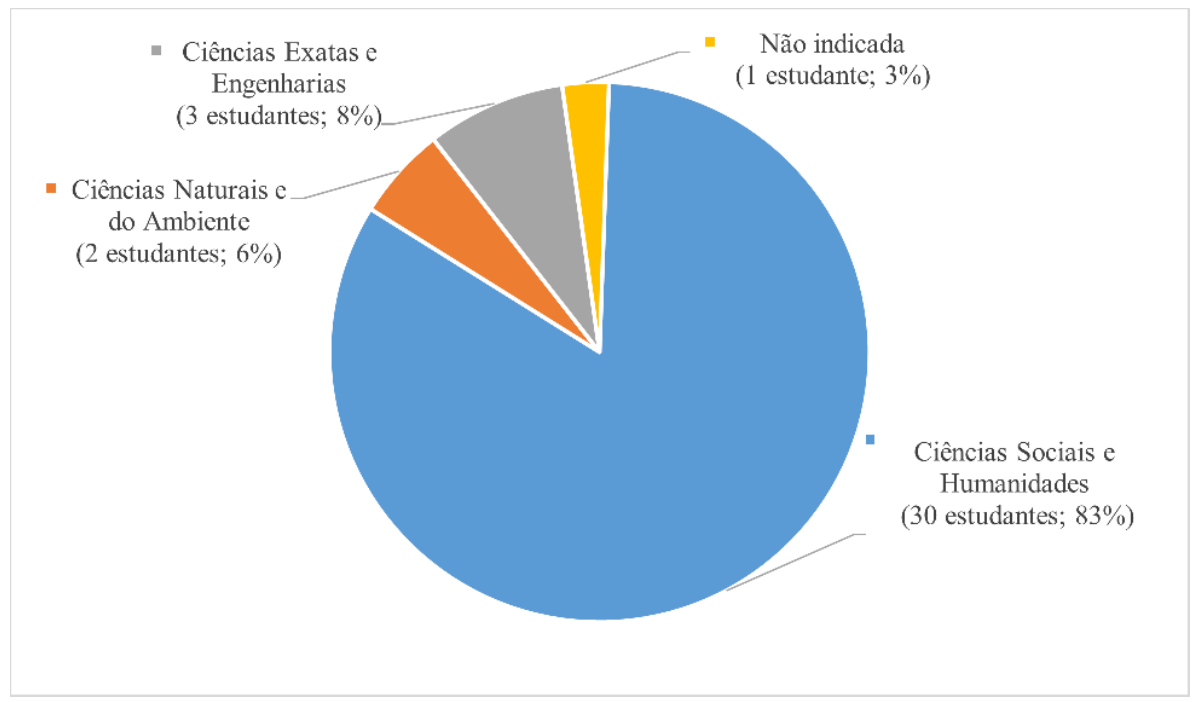

Desde logo, é necessário pensar metodologias de ensino que garantam a aquisição e a consolidação de conceitos e conhecimentos sociológicos, à partida mais difícil para estudantes sem contacto anterior ou continuado com a Sociologia. Assim, à necessidade de romper com as normas religiosas, morais, 
familiares e culturais que muitos/as estudantes/as trazem para a aula (Davis, 2005, p. 17), acresce a de distinguir a perspetiva sociológica de abordagens de carácter clínico, psicológico ou biológico (Mckinney, 1987, p. 303). Se acrescentarmos a este quadro as suas motivações pessoais, há que tornar os conteúdos programáticos operacionalizáveis não só do ponto de vista académico e profissional, mas também pessoal (Lee, 1993 p. 27).

A necessidade de conciliar estes diferentes propósitos tem conduzido à adoção de metodologias de ensino participativas que permitem, alternadamente, a partir da experiência dos/as estudantes (e.g., através de exercícios de role-playing ou relatos escritos de experiências pessoais), da análise de casos reais (e.g., através da visualização de filmes históricos, documentários ou notícias de imprensa) e da discussão de artigos científicos, facilitar a aquisição de conhecimentos básicos nos domínios do género e da sexualidade. Estes suportes são usados para despertar a discussão em aula. Os/as estudantes recebem previamente um guião que orienta a execução do exercício. Esta estratégia tem permitido ampliar a reflexão acerca dos conteúdos programáticos, facilitando a compreensão de conceitos e teorias pela redução do seu grau de abstração. Por outras palavras, "Em vez de ensinar a teoria como verdade revelada, [...] incentiva[-se] os/as estudantes a testar a utilidade das teorias aplicando-as a questões levantadas" por temas substantivos (Berheide e Segal, 1985, p. 279).

Entre os materiais usados no início do semestre letivo em apreço para facilitar a compreensão da forma como o género normativo condiciona identidades e condutas, encontram-se duas reportagens da National Geographic Portugal (2017a, 2017b). O s/as estudantes receberam previamente um guião de leitura com 14 questões que requeriam: a identificação e definição de conceitos desconhecidos presentes nos tex $\operatorname{tos}^{4}$; u ma reflexão sobre as suas próprias experiências ligadas ao género; a identificação de diferentes sistemas de normas, valores e representações do género; uma reflexão sobre a forma como outras variáveis ${ }^{5}$ se intersectam com o género e afetam a sua expressão; uma reflexão sobre formas de promover a equidade, a inclusão e uma melhor compreensão do género no mundo de hoje.

Tendo as aulas funcionado exclusivamente de modo remoto na sequência da superveniência do SARS Cov-2, os textos foram disponibilizados numa plataforma digital que permite a interação continuada entre pequenos grupos de estudantes e entre estes/as e a docente, bem como a consulta de um registo detalhado da mesma. Quanto às questões do guião que requeriam uma reflexão sobre experiências pessoais, seguindo a recomendação de DelaMater, et al. (1994, p. 310), os/as estudantes foram previamente informados de que a revelação de informação de carácter pessoal era estritamente voluntária, não

4 E.g., andrógino; cisgénero; binarismo, expressão e marcador de género; intersexo...

5 E.g., raça, estatuto socioeconómico, religião, orientação sexual. 
sendo necessário disponibilizar qualquer registo escrito da mesma ou partilhá-la oralmente.

Os excertos que se seguem ilustram uma troca de ideias sobre a reportagem da National Geographic Portugal (2017b) que relata a diversidade de entendimentos acerca do que é e de como se faz um homem. Os/as estudantes fizeram a leitura do texto por comparação com as suas próprias experiências. Porém, a comparação entre culturas, sociedades e épocas históricas presente na reportagem incentivou a reflexão e facilitou a colocação do tema no plano supra-individual. É assim que Henrique ${ }^{6}$ parte do caso do irmão e da sua própria experiência para a influência da cultura popular na socialização de género:

Tendo visto o meu irmão mais novo a começar o primeiro ciclo, foi óbvio que, logo desde o primeiro dia, com os seus colegas, lhe foi transmitida uma imagem de como um homem se deve comportar. Esta imagem é muito divulgada e reforçada pelos ícones da cultura pop. O Bart Simpson retrata o perfeito rapaz rebelde enquanto a sua irmã mais nova retrata a rapariga estudiosa e obediente. Ambos são estereótipos muito repetidos tanto nas histórias, como na realidade. [...] Embora um dos mais repetidos lemas da masculinidade seja viver a vida sem dar importância às opiniões dos outros, nas ações, o oposto é verificado vezes sem conta. Para a maior parte, a masculinidade é um disfarce que nos permite interagir com outros homens seguindo rigorosas regras que, embora ninguém as explique diretamente, temos de saber ${ }^{7}$.

(Henrique, Opção UMinho)

A reação de Mariana a estas afirmações ilustra o enriquecimento da aprendizagem pela partilha de experiências:

Penso que o mesmo surge entre mulheres com aquilo que é ou não é 'feminino' o suficiente...

(Mariana, Opção UMinho)

A metodologia adotada leva a que, por vezes, sejam os/as próprios/as estudantes a interrogar-se sobre os fundamentos do género. Eis uma das mais interessantes interrogações levantadas a propósito de uma das afirmações presentes no texto em discussão:

6 Em cada excerto, os nomes dos/as estudantes foram substituídos por pseudónimos. É também indicado se o/a estudante está inscrito/a na Licenciatura em Sociologia ou noutro ciclo de estudos, caso em que se refere a Opção UMinho.

7 Itálicos nossos. 
Neste excerto, diz-se que poderá haver um fator, para além da socialização cultural, que poderá influenciar certos comportamentos. No entanto, foram efetuados alguns estudos onde não foram encontradas provas da existência de um cérebro feminino ou de um cérebro masculino. Estes estudos comprovam que o cérebro é, na realidade, um mosaico com características femininas e masculinas que podem estar mais ou menos presentes num indivíduo. Assim, não será a sociedade que, ao ditar o que é aceitável, ou não, para cada género, obriga a uma supressão de certas características?

(Luísa, Opção UMinho)

A partir dos contributos dos/as estudantes é, depois, possível introduzir conceitos sociológicos essenciais, discuti-los e consolidá-los através da clarificação da relação entre posições individuais, interação social e determinantes estruturais (Berheide e Segal, 1985; Lee, 1993; Mckinney, 1987). A diversidade interna de uma turma não levanta, portanto, apenas desafios pedagógicos significativos. Também oferece oportunidades.

\section{Conclusão}

O género e a sexualidade são domínios de conhecimento altamente politizados e propensos a investimentos emocionais e morais. Das temáticas tratadas ao tipo de questões levantadas, não se trata apenas de aprender a questionar os fundamentos da ordem ou analisar sociologicamente fenómenos sociais particulares. Frequentemente, os públicos que escolhem UC nestes domínios apresentam perfis sociodemográficos, atitudes, valores e representações favoráveis à aceitação da diversidade, mas também expectativas de melhorar o seu autoconhecimento e a sua capacidade de ação face a experiências ou situações vividas. Adicionando a este quadro a sua proveniência de percursos formativos distintos, a atividade docente pode tornar-se particularmente desafiante: por um lado, é preciso ensinar a pensar não só científica, mas também sociologicamente acerca dos fenómenos do género e da sexualidade; por outro, isto implica garantir um certo distanciamento face às circunstâncias pessoais

Neste artigo, dá-se conta da experiência de ensino e da estratégia pedagógica que tem sido seguida na lecionação da UC Género e Sexualidade ao longo de vários anos. Para esse efeito, recorre-se a dados empíricos provenientes de um inquérito a estudantes e de registos de avaliação da aprendizagem relativos a um recorte temporal específico - o ano letivo de 2020/2021 -, que são mobilizados com um duplo propósito: por um lado, sistematizar e consolidar as perceções subjetivas decorrentes da experiência docente e, por outro, mostrar em que medida a diversidade interna de uma turma pode ser encarada não como um obstáculo à aprendizagem, mas como fator incentivador 
desta. Ainda que os dados avançados tenham um carácter eminentemente exploratório, permitem perceber que é possível, através de estratégias pedagógicas interativas e participativas e a partir das experiências e inquietações pessoais dos/as estudantes, reduzir o grau de abstração de teorias e conceitos e melhorar a sua capacidade de refletir sobre os fenómenos sociais e de enquadrar sociologicamente as suas circunstâncias pessoais. Trata-se, pois, de os/as conduzir sucessivamente num percurso de aprendizagem académica, mas também pessoal e coletiva, contribuindo para a sua formação como cidadãs/ãos.

\section{Referências bibliográficas}

ABOIM, Sofia - Homossexualidade e bissexualidade: práticas, atração e orientação sexual. In FERREIR A, Pedro Moura; CABR AL, M anuel Villaverde (orgs.) - Sexualidades em Portugal: comportamento e riscos. Lisboa: Bizâncio, 2010. ISBN : 978-972-53-0461-7. p. 147-200.

ALVAREZ, Teresa; VIEIRA, Cristina Coimbra - O papel da educação no caminho que falta percorrer em Portugal na desconstrução dos estereótipos de género: breves reflexões. Exedra: Revista Científica [em linha]. 1 (2014), p. 9-17 [consult. 19 mar. 2021]. Disponível em https:// repositorioaberto.uab.pt/bitstream/10400.2/7128/1/sup14-8-17.pdf. ISSN: 1646-9526.

BERHEIDE, Catherine White; SEGAL, Marcia Texler - Teaching sex and gender: a decade of experience. Teaching Sociology. Washington, DC. ISSN: 0092055X. 12: 3 (1985), p. 267-283.

Davis, Nancy J.. Taking sex seriously: Challenges in teaching about sexuality. Teaching Sociology [em linha]. 33: 1 (2005), p. 16-31. [consult. 14 abr. 2021]. Disponível em https://journals. sagepub.com/doi/pdf/10.1177/0092055X0503300102. ISSN : 0092055X.

Decreto-Lei n. 55 de 6 de julho de 2018 da Presidência do Conselho de Ministros [em linha]. Diário da República I Série, n. 55/2018 129 [consult. 17 mar. 2021]. Disponível em https:// dre.pt/home/-/dre/115652962/details/maximized.

DELAMATER, John; H YDE, Janet Shibley; ALLGEIER, Elizabeth Rice - Teaching human sexuality: personalizing the impersonal lecture. Teaching Sociology. Washington, DC. ISSN : 0092055X. 22: 4 (1994), p. 309-318.

DUNCAN, Steven G [et. al.] - Survey of heteronormative attitudes and tolerance toward gender non-conformity in Mountain West undergraduate students. Frontiers in Psychology [em linha]. 10 (2019), p. 793. [consult. 15 abr. 2021]. Disponível em https://www.frontiersin.org/ articles/10.3389/fpsyg.2019.00793/full. ISSN 1664-1078. ISSN : 1664-1078

FR ANCIS, Dennis A - "A Gay Agenda": Troubling Compulsory Heterosexuality in a South African University Classroom. Teaching Sociology [em linha]. 49: 3 (2021), p. 278-290 [consult. 26 ag. 2021]. Disponível em https://journals.sagepub.com/doi/pdf/10.1177/0092055X211022472. ISSN : 1939-862X.

GRAUPE, Mareli Eliane; LOCKS, Geraldo Augusto; PEREIRA, Josilaine Antunes - Gênero e sexualidade no campo da educação: provocando descolamentos e inquietações. Educação Temática Digital [em linha]. 20: 3 (2018), p. 805-821. [consult. 10 mai. 2021]. Disponível em https://periodicos.sbu.unicamp.br/ojs/index.php/etd/article/view/8647072. ISSN: 1676-2592.

Grupo de Trabalho de Educação para a Cidadania - Estratégia Nacional de Educação para a Cidadania [em linha]. s.1.: República Portuguesa - XXI Governo Constitucional. 2017. 16 p. [consult. 1 jun. 2021]. Disponível em https://www.dge.mec.pt/sites/default/files/Projetos Curriculares/Aprendizagens_Essenciais/estrategia_cidadania_original.pdf. 
IM PETT, Emily A.; PEPLAU, Letitia A. - Sexual compliance: gender, motivational, and relationship perspectives. The Journal of Sex Research [em linha]. 40: 1 (2003), p. 87-100. ISSN : 0022-4499 [consult. 1 mar. 2021]. Disponível em https://www.tandfonline.com/doi/ abs/10.1080/00224490309552169. ISSN 1559-8519.

International Center for Research on Women (ICRW) - International Men and Gender Equality Survey (IMAGES) Survey Q uestionnaires. Men + Gender equality Policy Project [em linha]. s.l.: ICRW/ Instituto Promundo, 2011 [consult. 19 fev. 2021]. Disponível em https://www. icrw.org/wp-content/uploads/2016/10/International-Men-and-Gender-Equality-SurveyIM AGES.pdf.

KRAMER, Laura; MARTIN JR., George T. - Mainstreaming gender: some thoughts for the nonspecialist. Teaching Sociology. Washington, DC. ISSN: 0092055X. 16: 2 (1988), p. 133-140.

LEE, J. Teaching gender politics. Teaching Sociology. Washington, DC. ISSN 0092055X. 21 (1993), p. 26-32.

LIEBERM AN, Hallie - Teaching Gender Studies to Straight Men. Inside Higher Education [em linha]. 3 jan. 2017 [consult. 10 mai. 2021]. Disponível em https://www.insidehighered.com/ advice/2017/01/03/how-teach-gender-studies-classes-encourage-more-straight-males-enroll-essay.

MARQUES, Nelson - O tamanho importa: veja aqui o maior inquérito aos hábitos sexuais dos portugueses. Jornal Expresso [em linha]. 8 out. 2012 [consult. 10 out. 2012]. Disponível em https://expresso.pt/multimedia/infografia/o-tamanho-importa-veja-aqui-o-maior-inquerito-aos-habitos-sexuais-dos-portugueses=f757860.

M ATOS, Margarida Gaspar de [et. al.] - Educação sexual em Portugal: legislação e avaliação da implementação nas escolas. Psicologia, Saúde e Doenças [em linha]. 15: 2 (2014), p. 335-355 [consult. 14 abr. 2021]. Disponível em https://www.redalyc.org/pdf/362/36231460003.pdf. ISSN : 2182-8407.

MCKINNEY, Kathleen - Two issues in the teaching of the sociology of human sexuality: A sociological approach and an applied emphasis. Teaching Sociology. Washington, DC. ISSN 0092055X. 15: 3 (1987), p. 303-306.

MILLS, C. Wright - A imaginação sociológica. Rio de Janeiro: Zahar, 1972.

NANDA, Geeta - Compendium of Gender Scales [em linha]. Washington, DC: FHI 360/C-Change, 2011. p. 40 [consult. 19 fev. 2021]. Disponível em http://gender.careinternationalwikis.org/_media/c-change_gender_scales_compendium.pdf.

National Geographic Portugal - Como a identidade de género condiciona as nossas vidas: Primeira parte. National Geographic Portugal. Portugal. ISSN: 2182-5459. n. ${ }^{\circ}$ especial (2017a), p. 24-63.

NATIONAL GEOGRAPH IC PORTUGAL - Como a identidade de género condiciona as nossas vidas: Segunda parte. N ational Geographic Portugal. Portugal. ISSN : 2182-5459. n. ${ }^{\circ}$ especial (2017b), p. 76-105.

PINTO, J. Madureira - Propostas para o Ensino das Ciências Sociais. Porto: Edições Afrontamento, 1994. ISBN: 9789723603217.

SEIXAS, Tânia Raquel - A Estratégia Nacional de Educação para a Cidadania: práticas e desafios de docentes de Cidadania e Desenvolvimento. Maia: Instituto Universitário da Maia, 2020. Dissertação de mestrado.

VILAR, Duarte; FERREIRA, Pedro Moura; DUARTE, Sara - A educação sexual dos jovens portugueses: conhecimentos e fontes [em linha]. s.1.: Associação para o Planeamento da Família/ Instituto de Ciências Sociais da Universidade de Lisboa, 2008 [consult. 2 mar. 2021]. Disponível em http://www.apf.pt/sites/default/files/media/2016/artigo_versao_final_ para_site.pdf. 
- Receção: 15.06.2021

- Aprovação: 20.09.2021 
Ana Maria Brandão | Sérgio Anônio Silva Rêgo | Joana Teixeira Ferraz da Silva 